\title{
Self-Monitoring of Blood Glucose and Hypoglycemia Association During Fasting in Ramadan Among Patients with Diabetes
}

This article was published in the following Dove Press journal: Diabetes, Metabolic Syndrome and Obesity: Targets and Therapy

\author{
Deyaa Mansouri (1D' \\ Ebtehal Khayat ${ }^{2}$ \\ Mohannad Khayat ${ }^{3}$ \\ Muteb Aboawja ${ }^{4}$ \\ Areej Aseeri ${ }^{5}$ \\ Faisal Banah ${ }^{6}$ \\ Khulood Alsiary $\mathbb{B D}^{7}$ \\ Lama Abdulaziz Rammal (iD) \\ Adel D Almalki ${ }^{8}$ \\ Mohammed Hasaballah ${ }^{9}$ \\ 'Hera General Hospital, Mecca, Saudi \\ Arabia; ${ }^{2}$ Joint Program of Family \\ Medicine, Mecca, Saudi Arabia; ${ }^{3}$ Joint \\ Program of Community Medicine, Mecca, \\ Saudi Arabia; ${ }^{4}$ King Faisal Medical City, \\ Abha, Saudi Arabia; ${ }^{5}$ King Fahad Military \\ Medical Complex, Dhahran, Saudi Arabia; \\ ${ }^{6}$ Armed Hospital Southen Rigon, \\ KhamisMushait, Saudi Arabia; ${ }^{7}$ King \\ Abdulaziz Medical City, Jeddah, Saudi \\ Arabia; ${ }^{8}$ King Salman Bin Abdulaziz \\ Hospital, Riyadh, Saudi Arabia; ${ }^{9}$ King \\ Faisal Hospital, Mecca, Saudi Arabia
}

Correspondence: Deyaa Mansouri

Hera General Hospital, Mecca, Saudi

Arabia

Email dr_deyaa@hotmail.com
Purpose: The study aims to assess current practices of patients with diabetes to control blood glucose levels during Ramadan.

Patients and Methods: A cross-sectional approach has been used for collecting data through a structured and interview-based questionnaire to assess the association between self-monitoring of blood glucose (SMBG) and hypoglycemia. The questionnaire has recorded information about demographics, duration of diabetes, and treatment of diabetes, and hypoglycemia complications faced during Ramadan. The primary outcomes of this study include frequency of SMBG during fasting in Ramadan and association of SMBG and hypoglycemia and break of fasting. However, the secondary outcomes include medications, glycemic control, and other influencing factors. The data was analyzed using Statistical Package of Social Sciences (SPSS) version 20.

Results: The findings have shown that the majority of the patients used a combination of metformin+sulphonylurea $(23.02 \%)$ following metformin+insulin (20.86\%), insulin (12.94\%), and metformin (8.63\%). Whereas diet control, high or low blood sugar, insulin dose adjustment in fasting conditions were the most influential factors during Ramadan when the blood sugar levels were tested. Majority of the patients monitored their blood glucose level during pre-iftar (56.8\%) following to hypoglycemia $(30.2 \%)$, post-iftar $(29.4 \%)$, and rarely monitored in afternoon (3.5\%) despite that only $10.1 \%$ monitored their blood glucose on a daily basis. Patients who had symptoms of hypoglycemia and had to break their fasting at least once were $41 \%$ and $27.2 \%$, respectively. There is a significant association between age and gender with symptoms of low blood sugar level. Additionally, a significant association between blood sugar monitoring and high blood sugar level has been shown $(p=0.041)$, indicating that lack in daily blood sugar monitoring can increase the blood sugar level of a patient during Ramadan.

Conclusion: The present study has helped in providing better understanding about the selfmonitoring of blood glucose level and hypoglycemia. Furthermore, it also emphasizes the pre-Ramadan education about when to break their fasting along with frequency and timing of SMBG.

Keywords: glycemic control, insulin, medication, metformin, sulphonylurea

\section{Introduction}

The prevalence of diabetes has increased in recent decades at a massive rate, regardless of age groups. Developing countries have seen an increase in the prevalence of diabetes due to a variety of reasons; some of which are a sedentary lifestyle and poor-quality nutrition. It is expected to rise from about 415 million, to a burgeoning 642 million patients with 
diabetes in the year 2040. ${ }^{1}$ In 2015, there were three Muslimmajority countries, Bangladesh, Indonesia, and Egypt, amongst the top 10 countries having adults suffering from diabetes. $^{2}$ There is a widespread prevalence of obesity due to increasing wealth and westernization in the Arabian Gulf. Moreover, there is also an increase in the dietary consumption and energy-dense food. In addition, the adoption of a sedentary lifestyle with the least amount of exercise and physical activity have worsened the problem.

Patients on a glucose control plan either for medical reasons or for religious reasons; like fasting in Ramadan, undergo a risk of suffering from hypoglycemia. Patients with diabetes must be very cautious when fasting during Ramadan as fasting can lead to low blood sugar; a condition known as hypoglycemia. Patients who insist on fasting, despite the risks associated with it, pose a medical challenge for the health-care professionals and for themselves. ${ }^{3}$ Delayed or missed meals and limited or no consumption of fluids vastly contribute to cause hypoglycemia. There are many other causes of hypoglycemia like, renal dysfunction, cognitive dysfunction, concomitant medications, old age, and long duration of diabetes. ${ }^{4}$ The main cause of hypoglycemia is the use of glucose-lowering medications that are used to increase the circulating insulin. The treatment of patients with type 2 diabetes with antihyperglycemic medications vastly increases the risk of hypoglycemia. ${ }^{5}$

Patients with diabetes who are at a high risk of major complications during fasting in Ramadan may face severe hypoglycemia. Moreover, patients undergoing dialysis treatment, performing intense physical labor, pregnant women, and patients with advanced macrovascular complications of the brain, heart, or peripheral vessels are recommended against fasting in Ramadan. Patients who are at moderate risk of complications during fasting, and insist on fasting, must adhere to dietary advice given by their physicians. Furthermore, efficient meal planning and a balanced diet will ensure more safety. A low glycemic index diet consists of moderate consumption of carbohydrates and proteins, lower fat, higher fiber, and fresh vegetables and fruits. ${ }^{6}$ Besides these dietary modifications, self-monitoring of blood glucose (SMBG) is another effective method in efficient management of hypoglycemic conditions in patients with diabetes.

Islam exempts a person from fasting when it may significantly affect the health of the faster or when an individual is sick. However, use of a glucose meter is one measure of precaution employed by patients with diabetes during Ramadan. Diabetes management with medications and consistent monitoring is an effective strategy to prevent long-term complications of diabetes. SMBG is an essential requirement for patients with diabetes, who need to adjust their insulin doses on a regular basis. Therefore, the advantages of SMBG cannot be overstated; although it requires adequate handling and storage and proper performance of the quantifying process. ${ }^{7}$ The use of SMBG is widely recommended by health-care professionals and diabetes specialists. It is effective to prevent hypoglycemia and to achieve a safe level of glycemic control. In SMBG, the patient collects detailed information about blood glucose levels at different points of time throughout the day. It enables the physician to provide the patient with the precise amount of medication to maintain constant glucose levels. Subsequently, the patient can also adjust physical activity and dietary routine to improve their glycemic control on a regular basis. ${ }^{8}$

One of the standard methods to monitor the glycemia level is through glycated hemoglobin test, which is done at three-month intervals. Patients suffering from type 2 diabetes must try to keep their HbA1c measurements at $6.5 \%$, but a physician can best customize the ideal level of HbAlc according to patient's history and other parameters. The HbA1c does not monitor patients on a regular basis. The patients need to discuss the dietary regimen during fasting, their medication schedules and other aspects related to diabetes. However, SMBG is a boon for patients with diabetes. This test can be done at any time of the day, before or after a physical activity, or between meals. It is handy and can be personally used by patients. ${ }^{9}$ Besides, it is very affordable and advisable that all patients with diabetes have a blood sugar monitor at home. This is because Muslims usually go for very high calorie food, they sleep and work for fewer hours, and they do not exercise during Ramadan. Moreover, there is limited data on controlling diabetes in Ramadan, despite the large number of Muslim populations globally. Therefore, the present study aims to assess current practices of diabetic patients to control blood glucose levels during Ramadan.

\section{Materials and Methods}

Ethical Approval: $\mathrm{MoH}$ in Saudi Arabia approved this study. It was a face to face interview after getting verbal consent from the participants. The study was in accordance with the Declaration of Helsinki.

This cross-sectional study was conducted through an interview-based questionnaire. The study subjects were a representative group of patients with diabetes, among which 139 patients were selected, who attended clinic during the second 
and third week following completion of fasting in Ramadan. All the patients with diabetes attending the participating clinic at the time of the study, practicing SMBG, and fasting most of Ramadan (more than 15 days) were included in the study. The exclusion criteria for this study were patients with diabetes who were under 18 years of age.

During the second and third week following completion of fasting in Ramadan, all patients with diabetes attending participating clinics were requested to be interviewed using the questionnaire. Consent was obtained from all study participants before introducing the questionnaire. A closeended questionnaire was used to assess knowledge and awareness about Ramadan fasting of the study population. Frequency of SMBG during fasting in Ramadan and association of SMBG and hypoglycemia and break of fasting were primary outcomes of this study. Medications, glycemic control, and influencing factors were secondary outcomes. The obtained data was entered into Microsoft Excel and then transferred to SPSS version 20 (IBM Corporation, Armonk, NY, USA) for conducting further analysis. The data is presented in form of frequencies and percentages since it is descriptive.

\section{Results}

Table 1 depicts the demographic details of the patients. A total of $66.9 \%$ male and $33.1 \%$ female patients participated in the study. Mostly patients were treated with metformin + sulphonylurea $(23.02 \%)$, metformin + insulin $(20.86 \%)$, and insulin (12.94\%). Table 2 presents influential factors contributing toward the hypoglycemia and break of fasting.

Table 3 presents the types of medicines used by patients during Ramadan. Most of the patients used a combination of metformin+sulphonylurea $(23.02 \%)$ following metformin+insulin (20.86\%), insulin (12.94\%), metformin (8.63\%), and metformin+sulphonylurea + glitazones (7.194\%). Metformin alone was taken by $8.63 \%$ of the patients, whereas metformin in combination to other drugs was taken by $72.66 \%$ of the patients.

Table 4 presents blood glucose level monitored by patients during Ramadan at different times. Most of the patients monitored their blood glucose level during preiftar (14.3\%) following hypoglycemic condition (10.07\%), post-iftar $(7.913 \%)$, pre-iftar + pre-sahoor $(7.194 \%)$, and pre-iftar + pre-sahoor + hypoglycemic $(6.748 \%)$. Findings of Table 5 show that $56.83 \%$ and $29.49 \%$ patients mon-
Table I Demographic Details

\begin{tabular}{|c|c|c|c|}
\hline Measure & Items & Frequency & $\begin{array}{l}\text { Percentage } \\
\text { (\%) }\end{array}$ \\
\hline \multirow[t]{2}{*}{ Gender } & Male & 93 & 66.9 \\
\hline & Female & 46 & 33.1 \\
\hline New & Yes & 44 & 32.1 \\
\hline medicine & No & 94 & 67.9 \\
\hline Information & Yes & 65 & 47.1 \\
\hline about testing & No & 72 & 52.8 \\
\hline \multirow[t]{7}{*}{ Days a week } & I day & 48 & 34.5 \\
\hline & 2 days & 29 & 20.9 \\
\hline & 3 days & 27 & 19.4 \\
\hline & 4 days & 8 & 5.8 \\
\hline & 5 days & 3 & 2.2 \\
\hline & 6 days & 1 & 0.7 \\
\hline & 7 days & 14 & 10.1 \\
\hline \multirow[t]{7}{*}{ Times a day } & Once & 78 & 56.1 \\
\hline & Twice & 36 & 25.9 \\
\hline & 3 times & 10 & 7.2 \\
\hline & 4 times & 4 & 2.9 \\
\hline & 5 times & I & 0.7 \\
\hline & 6 times & 1 & 0.7 \\
\hline & 7 times & 1 & 0.7 \\
\hline \multirow{2}{*}{$\begin{array}{l}\text { Feeling of } \\
\text { symptoms }\end{array}$} & Yes & 59 & 42.4 \\
\hline & No & 80 & 57.6 \\
\hline \multirow{6}{*}{$\begin{array}{l}\text { Breaking } \\
\text { fasts }\end{array}$} & Once & 23 & 16.5 \\
\hline & Twice & 7 & 5 \\
\hline & 3 times & 6 & 4.3 \\
\hline & 4 times & 1 & 0.7 \\
\hline & More than 6 times & I & 0.7 \\
\hline & $\begin{array}{l}\text { Total number of } \\
\text { breaking fast }\end{array}$ & \multicolumn{2}{|l|}{38} \\
\hline \multirow{8}{*}{$\begin{array}{l}\text { Episodes of } \\
\text { low blood } \\
\text { level }\end{array}$} & Once & 16 & 11.5 \\
\hline & Twice & 15 & 10.8 \\
\hline & 3 times & 14 & 10.1 \\
\hline & 4 times & 4 & 2.9 \\
\hline & 5 times & 1 & 0.7 \\
\hline & 6 times & 6 & 4.3 \\
\hline & More than 6 times & 1 & 0.7 \\
\hline & $\begin{array}{l}\text { Total number of low } \\
\text { blood level episodes }\end{array}$ & \multicolumn{2}{|l|}{57} \\
\hline \multirow{6}{*}{$\begin{array}{l}\mathrm{HbAlc} \\
\text { reading }\end{array}$} & Under $6.5 \%$ & 12 & 8.6 \\
\hline & $6.6-7.5 \%$ & 20 & 14.4 \\
\hline & $7.6-8.5 \%$ & 29 & 20.9 \\
\hline & $8.6-9.5 \%$ & 9 & 6.5 \\
\hline & $9.6-10.5 \%$ & 6 & 4.3 \\
\hline & Over $10.5 \%$ & 8 & 5.8 \\
\hline
\end{tabular}


Table 2 Table Depicting the Influential Factors

\begin{tabular}{|c|c|c|c|c|c|c|c|}
\hline Factors & $\begin{array}{l}\text { Not at All } \\
\text { Influential } \\
\text { N (\%) }\end{array}$ & $\begin{array}{l}\text { Low } \\
\text { Influential } \\
\text { N (\%) }\end{array}$ & $\begin{array}{l}\text { Slightly } \\
\text { Influential } \\
\text { N (\%) }\end{array}$ & $\begin{array}{l}\text { Neutral } \\
\text { N (\%) }\end{array}$ & $\begin{array}{l}\text { Moderately } \\
\text { Influential } \\
\text { N (\%) }\end{array}$ & $\begin{array}{l}\text { Very } \\
\text { Influential } \\
\text { N (\%) }\end{array}$ & $\begin{array}{l}\text { Extremely } \\
\text { Influential } \\
\text { N (\%) }\end{array}$ \\
\hline Low blood sugar & $53(38.1)$ & $13(9.4)$ & $8(5.8)$ & $4(2.9)$ & $16(11.5)$ & $19(13.7)$ & $26(18.7)$ \\
\hline High blood sugar & $48(34.5)$ & $16(11.5)$ & $14(10.1)$ & $13(9.4)$ & $3(2.2)$ & $16(11.5)$ & $29(20.9)$ \\
\hline $\begin{array}{l}\text { Advice of health-care } \\
\text { professional }\end{array}$ & $13(9.4)$ & $14(10.1)$ & $10(7.2)$ & $29(20.9)$ & $31(22.3)$ & $18(12.9)$ & $24(17.3)$ \\
\hline Controlling diet & $23(16.5)$ & $18(12.9)$ & $12(8.6)$ & $17(12.2)$ & $24(17.3)$ & $19(13.7)$ & $26(18.7)$ \\
\hline Adjusting insulin dose & $7(5)$ & $5(3.6)$ & $5(3.6)$ & $17(12.2)$ & $13(9.4)$ & $13(9.4)$ & $16(11.5)$ \\
\hline $\begin{array}{l}\text { Keeping an eye on blood } \\
\text { sugar }\end{array}$ & $20(14.4)$ & $17(12.2)$ & $15(10.8)$ & $20(14.4)$ & $17(12.2)$ & $24(17.3)$ & $22(15.8)$ \\
\hline Starting change therapy & $27(19.4)$ & II (7.9) & $10(7.2)$ & $23(16.5)$ & $21(15.1)$ & $20(14.4)$ & $25(18)$ \\
\hline Fasting condition & $37(26.6)$ & $9(6.5)$ & $5(3.6)$ & $31(22.3)$ & $25(18)$ & $15(10.8)$ & $17(12.2)$ \\
\hline Stabilizing blood sugar & $38(27.3)$ & $14(10.1)$ & $10(7.2)$ & $28(20.1)$ & $16(11.5)$ & $16(11.5)$ & $15(10.8)$ \\
\hline $\begin{array}{l}\text { Regular hypoglycemic } \\
\text { attacks }\end{array}$ & 51 (36.7) & II (7.9) & $7(5)$ & $12(8.6)$ & $9(6.5)$ & $24(17.3)$ & $23(16.5)$ \\
\hline $\begin{array}{l}\text { Severe hypoglycemic } \\
\text { Attack }\end{array}$ & $57(4 I)$ & $8(5.8)$ & $4(2.9)$ & II (7.9) & $9(6.5)$ & I6 (II.5) & 33 (23.7) \\
\hline
\end{tabular}

Table 3 Types of Medicine

\begin{tabular}{|l|l|l|}
\hline Items & $\mathbf{N}$ & $\%$ \\
\hline Metformin & 12 & 8.63 \\
DPP4i & 0 & 0 \\
Sulphonylurea & 0 & 0 \\
Glitazones & 0 & 0 \\
Insulin & 18 & 12.94 \\
Metformin+insulin & 29 & 20.86 \\
Metformin+sulphonylurea & 32 & 23.02 \\
Metformin+DPP4i & 4 & 2.877 \\
Metformin+glitazones & 2 & 1.438 \\
Metformin+others & 5 & 3.597 \\
DPP4i+glitazones+insulin & 1 & 0.719 \\
DPP4i+sulphonylurea & 2 & 1.438 \\
Sulphonylurea+glitazones & 1 & 0.719 \\
Sulphonylurea+insulin & 1 & 0.719 \\
Sulphonylurea+others & 1 & 0.719 \\
Metformin+DPP4i+insulin & 3 & 2.158 \\
Metformin+sulphonylurea+insulin & 6 & 4.316 \\
Metformin+sulphonylurea+glitazones & 10 & 7.194 \\
Metformin+sulphonylurea+DPP4i & 8 & 5.755 \\
Metformin+DPP4i+insulin+sulphonylurea & 2 & 1.438 \\
Missing & 1 & 0.719 \\
Others & 1 & 0.719 \\
Total & 139 & 100 \\
\hline
\end{tabular}

itored blood glucose level at pre-iftar and post-iftar, respectively. Moreover, $22.30 \%$ of participants monitored their blood glucose level at pre-sahoor.

Table 6 shows the factors influencing patients during Ramadan as they test their blood sugar. The results indicate that low/high
Table 4 Blood Glucose Level Monitoring

\begin{tabular}{|l|l|l|}
\hline Items & N & $\%$ \\
\hline Afternoon & 3 & 2.158 \\
Pre-iftar & 20 & 14.388 \\
Post-iftar & 11 & 7.913 \\
Pre-sahoor & 5 & 3.59 \\
When unwell & 7 & 5.035 \\
Hypoglycemic & 14 & 10.07 \\
Post-iftar+pre-sahoor & 3 & 2.158 \\
Post-iftar+hypoglycemic & 2 & 1.438 \\
Pre-iftar+hypoglycemic & 8 & 5.755 \\
Pre-iftar+pre-sahoor & 10 & 7.194 \\
Pre-iftar+when unwell & 6 & 4.316 \\
Post-iftar+unwell & 2 & 1.438 \\
Pre-iftar+post-iftar & 10 & 7.194 \\
Pre-iftar+post-iftar+unwell & 1 & 0.719 \\
Afternoon+pre-iftar+unwell & 1 & 0.719 \\
Pre-iftar+post-iftar+pre-sahoor & 3 & 2.158 \\
Pre-iftar+post-iftar+pre-sahoor+hypoglycemic & 1 & 0.719 \\
Pre-iftar+post-iftar+others & 1 & 0.719 \\
Afternoon+pre-iftar+post-iftar & 1 & 0.719 \\
Pre-iftar+when unwell+hypoglycemic & 2 & 1.438 \\
Pre-iftar+pre-sahoor+ypoglycemic & 9 & 6.748 \\
Pre-iftar+post-iftar+when unwell+hypoglycemic & 6 & 4.316 \\
Others & 6 & 6.748 \\
Missing & 8 & 5.755 \\
Total & 139 & 100 \\
\hline
\end{tabular}

blood sugar, diet control, insulin dose, and adjustment in fasting conditions were the most influential factors. Table 7 shows significant association of age and gender with symptoms of low blood 
Table 5 Blood Glucose Level Monitoring Timing

\begin{tabular}{|l|l|l|}
\hline Items & N & \% \\
\hline Afternoon & 5 & 3.59 \\
Pre-iftar & 79 & 56.8 \\
Post-iftar & 41 & 29.49 \\
Pre-sahoor & 31 & 22.30 \\
When unwell & 25 & 17.98 \\
Hypoglycemia & 42 & 30.21 \\
Random & 7 & 5.03 \\
\hline
\end{tabular}

sugar level. Moreover, gender was significantly associated with SMBG level, which indicates that there is significant variation in SMBG level with respect to both genders. In the context of breaking fast, there was no significant association of selfmonitoring indicators, which shows no influence on breaking fast during Ramadan.

\section{Discussion}

The present study provided a better emphasis toward the SMBG regimen education during fasting. These findings are supported by Ko et al, ${ }^{10}$ who investigated the importance of patient education as part of care of patients with diabetes. The results depicted that $\mathrm{HbA} 1 \mathrm{c}$ of the control group was found to be higher than the patients who had undergone the SIDEP education program. It was also discovered that the patients who underwent the SIDEP were taking better care of themselves through the SMBG regimen. Conversely, the control group patients were lacking in self-care. It was concluded that a professional and thorough patient education program proved indispensable for patients suffering from diabetes. ${ }^{10}$

The present study showed that self-monitoring behavior of the patients during fasting was influenced by low/ high blood sugar, diet control, insulin dose, and adjustment

Table 6 Controlling Blood Glucose Level Among the Diabetic Patients

\begin{tabular}{|c|c|c|c|c|c|c|c|}
\hline & $\begin{array}{l}\text { Not at All } \\
\text { Influential } \\
\text { N (\%) }\end{array}$ & $\begin{array}{l}\text { Low } \\
\text { Influential } \\
\text { N (\%) }\end{array}$ & $\begin{array}{l}\text { Slightly } \\
\text { Influential } \\
\text { N (\%) }\end{array}$ & $\begin{array}{l}\text { Neutral } \\
\text { N (\%) }\end{array}$ & $\begin{array}{l}\text { Moderately } \\
\text { Influential } \\
\text { N (\%) }\end{array}$ & $\begin{array}{l}\text { Very } \\
\text { Influential } \\
\text { N (\%) }\end{array}$ & $\begin{array}{l}\text { Extremely } \\
\text { Influential } \\
\mathbf{N}(\%)\end{array}$ \\
\hline Low blood sugar & $53(38.1)$ & $13(9.4)$ & $8(5.8)$ & $4(2.9)$ & $16(11.5)$ & $19(13.7)$ & $26(18.7)$ \\
\hline High blood sugar & $48(34.5)$ & $16(11.5)$ & $14(10.1)$ & $13(9.4)$ & $3(2.2)$ & $16(11.5)$ & $29(20.9)$ \\
\hline $\begin{array}{l}\text { Healthcare } \\
\text { professional advice }\end{array}$ & $13(9.4)$ & $14(10.1)$ & $10(7.2)$ & $29(20.9)$ & $31(22.3)$ & $18(12.9)$ & $24(17.3)$ \\
\hline Diet control & $23(16.5)$ & $18(12.9)$ & $12(8.6)$ & $17(12.2)$ & $24(17.3)$ & $19(13.7)$ & $26(18.7)$ \\
\hline $\begin{array}{l}\text { Insulin dose } \\
\text { adjustment }\end{array}$ & $7(5)$ & $5(3.6)$ & $5(3.6)$ & $17(12.2)$ & $13(9.4)$ & $13(9.4)$ & $16(11.5)$ \\
\hline Fasting condition & $37(26.6)$ & $9(6.5)$ & $5(3.6)$ & $31(22.3)$ & $25(18)$ & $15(10.8)$ & $17(12.2)$ \\
\hline
\end{tabular}

Table 7 Blood Glucose Level Monitoring Either Alone or in Combination

\begin{tabular}{|c|c|c|c|c|c|c|}
\hline & \multicolumn{2}{|c|}{$\begin{array}{l}\text { Symptoms of Low Blood Sugar } \\
\text { Level }\end{array}$} & \multicolumn{2}{|c|}{ Episode of Low Blood Sugar } & \multicolumn{2}{|l|}{ Break Fasting } \\
\hline & $\begin{array}{l}\text { Correlation } \\
\text { Value }(r)\end{array}$ & $\begin{array}{l}\text { Significance } \\
\text { Value }(p)\end{array}$ & $\begin{array}{l}\text { Correlation } \\
\text { Value }(r)\end{array}$ & $\begin{array}{l}\text { Significance } \\
\text { Value }(p)\end{array}$ & $\begin{array}{l}\text { Correlation } \\
\text { Value }(r)\end{array}$ & $\begin{array}{l}\text { Significance } \\
\text { Value }(p)\end{array}$ \\
\hline Age & -0.175 & 0.040 & 0.082 & 0.545 & -0.241 & 0.145 \\
\hline Gender & 0.262 & 0.002 & 0.374 & 0.004 & 0.163 & 0.328 \\
\hline Diabetes & 0.075 & 0.388 & -0.204 & 0.128 & -0.99 & 0.556 \\
\hline Types of medicines & -0.123 & 0.151 & -0.044 & 0.749 & 0.127 & 0.455 \\
\hline New medicine & 0.139 & 0.103 & 0.105 & 0.443 & 0.012 & 0.942 \\
\hline $\begin{array}{l}\text { Testing blood } \\
\text { sugar level }\end{array}$ & 0.103 & 0.229 & 0.218 & 0.106 & -0.119 & 0.484 \\
\hline Days a week & -0.013 & 0.881 & -0.11 & 0.936 & 0.037 & 0.827 \\
\hline Times a day & 0.007 & 0.941 & 0.020 & 0.883 & 0.168 & 0.314 \\
\hline $\begin{array}{l}\text { Blood glucose } \\
\text { monitoring }\end{array}$ & -0.001 & 0.991 & 0.028 & 0.836 & 0.033 & 0.844 \\
\hline
\end{tabular}


in fasting conditions. A similar study conducted by Farmer et $\mathrm{al}^{11}$ found that increased frequency of SMBG was associated with increased frequency of self-reported episodes of low blood glucose, even among patients not taking insulin or sulfonylureas. ${ }^{11}$ The present study also showed that most of the patients during fasting monitored their blood sugar levels at pre-iftar and when experiencing hypoglycemic symptoms despite that only $10.1 \%$ monitored their blood glucose on a daily basis. However, Mansouri et $\mathrm{al}^{12}$ showed that $28.2 \%$ of the patients monitored their blood glucose on a daily basis, while $10.6 \%$ monitored it more than once daily.

The present study has highlighted the importance of using SMBG among the patients with diabetes during Ramadan. This was confirmed by Alamoudi et al $^{13}$ who stated that use of SMBG might help the patients with diabetes to have fewer episodes of hypoglycemia, lower weight, and better glucose control compared with usual care. Another study examining the impact of customized type 2 diabetes education program on clinical consequences during Ramadan showed that patients with type 2 diabetes were more likely to modify their diabetes treatment plan (97\% vs 88\%), reduce their body mass index and glycated hemoglobin. ${ }^{14}$

The present study is informative as it also highlights the significance of clinically important data of patients with diabetes during Ramadan fasting. However, the results are limited because it has focused on a small sample and it has limited statistical power as it is an exploratory study. The study lacks analysis of other potentially confounding factors such as age, parity, BMI, personal, and family history.

\section{Conclusion}

The study has assessed the association between SMBG and managing the hypoglycemic condition among patients with diabetes. The study results depicted that low blood sugar level differs with respect to age and gender. The study has provided better understanding about the SMBG level and hypoglycemia frequencies during fasting in Ramadan. It shows that self-monitoring of blood sugar level differs with respect to gender of the patients. Moreover, none of the selfmonitoring indicators were influential in breaking fast of the patients during the Ramadan. Considering the study results, the use of SMBG is emphasized during Ramadan as recommended by health-care professionals and diabetes specialists.

Moreover, the study recommends that diabetic patients need to be encouraged and guided for changing their lifestyle during Ramadan to minimize the risk of developing acute complications. It also recommends continuous glucose monitoring to be studied for understanding the blood glucose changes in patients with diabetes during Ramadan. In the similar context, public health programs also need to be developed and implemented before Ramadan to address the diabetes management that would promote safe fasting practices and avoid any complications.

\section{Acknowledgments}

The authors are very thankful to all the associated personnel in any reference that contributed in/for the purpose of this research.

\section{Disclosure}

The authors report no conflicts of interest in this work.

\section{References}

1. Ogurtsova K, da Rocha Fernandes JD, Huang Y, et al. IDF diabetes atlas: global estimates for the prevalence of diabetes for 2015 and 2040. Diabetes Res Clin Pract. 2017;128:40-50. doi:10.1016/j. diabres.2017.03.024

2. Babineaux SM, Toaima D, Boye KS, et al. Multi-country retrospective observational study of the management and outcomes of patients with Type 2 diabetes during Ramadan in 2010 (CREED). Diabet Med. 2015;32:819-828. doi:10.1111/dme.12685

3. Al-Arouj M, Assaad-Khalil S, Buse J, et al. Recommendations for management of diabetes during Ramadan: update 2010. Diabetes Care. 2010;33:1895-1902. doi:10.2337/dc10-0896

4. Abdelhafiz AH, Rodríguez-Mañas L, Morley JE, Sinclair AJ. Hypoglycemia in older people-a less well recognized risk factor for frailty. Aging Dis. 2015;6:156. doi:10.14336/AD.2014.0330

5. Al Sifri S, Basiounny A, Echtay A, et al. The incidence of hypoglycaemia in Muslim patients with type 2 diabetes treated with sitagliptin or a sulphonylurea during Ramadan: a randomised trial. Int $J$ Clin Pract. 2011;65:1132-1140. doi:10.1111/j.1742-1241.2011.02797.x

6. Jaleel M, Fathima F, Raza S, Jaleel BN. Ramadan and diabetes: as-Saum (The fasting). Indian J Endocrinol Metab. 2011;15:268. doi:10.4103/2230-8210.85578

7. Erbach M, Freckmann G, Hinzmann R, et al. Interferences and limitations in blood glucose self-testing: an overview of the current knowledge. J Diabetes Sci Technol. 2016;10:1161-1168. doi:10. 1177/1932296816641433

8. Bener A, Yousafzai MT. Effect of Ramadan fasting on diabetes mellitus: a population-based study in Qatar. J Egypt Public Health Assoc. 2014;89:47-52. doi:10.1097/01.EPX.0000451852.92252.9b

9. Clar C, Barnard K, Cummins E, Royle P, Waugh N. Self-monitoring of blood glucose in type 2 diabetes: systematic review. Health Technol Assess. 2010;14. doi:10.3310/hta14120

10. Ko SH, Song KH, Kim SR, et al. Long-term effects of a structured intensive diabetes education programme (SIDEP) in patients with Type 2 diabetes mellitus-a 4-year follow-up study. Diabet Med. 2007;24:55-62. doi:10.1111/j.1464-5491.2007.02013.x

11. Farmer A, Balman E, Gadsby R, et al. Frequency of self-monitoring of blood glucose in patients with type 2 diabetes: association with hypoglycaemic events. Current Medical Research and Opinion. 2008;24:11,3097-3104. doi:10.1185/03007990802473062 
12. Mansouri DA, Alawi HH, Barasyn KB, et al. Self-monitoring of blood glucose among diabetic patients attending Al-Eskan Primary Health Care Center in Makkah Al-Mukarramah city. Int J Med Sci Public Health. 2015;4:527. doi:10.5455/ijmsph.2015.25012015109

13. Alamoudi R, Alsubaiee M, Alqarni A, Aljaser S, Saleh Y, Eledrisi M. Attitudes and habits of patients with type 1 diabetes during fasting Ramadan. J Clin Transl Endocrinol. 2018;14:1-4. doi:10.1016/j.jcte. 2018.09.001
14. McEwen LN, Ibrahim M, Ali NM, et al. Impact of an individualized type 2 diabetes education program on clinical outcomes during Ramadan. BMJ Open Diabetes Res Care. 2015;3:e00111. doi:10. 1136/bmjdrc-2015-000111

\section{Publish your work in this journal}

Diabetes, Metabolic Syndrome and Obesity: Targets and Therapy is an international, peer-reviewed open-access journal committed to the rapid publication of the latest laboratory and clinical findings in the fields of diabetes, metabolic syndrome and obesity research. Original research, review, case reports, hypothesis formation, expert opinion and commentaries are all considered for publication. The manuscript management system is completely online and includes a very quick and fair peer-review system, which is all easy to use. Visit http://www.dovepress.com/testimonials.php to read real quotes from published authors. 